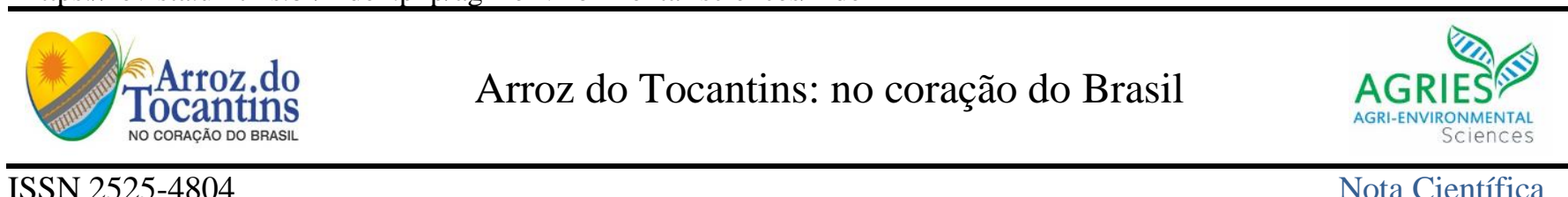

\title{
CONTRIBUIÇÃO DAS CULTIVARES DE ARROZ DA EMBRAPA NA PRODUÇÃO DE ARROZ IRRIGADO NO ESTADO DO TOCANTINS
}

\author{
Daniel de Brito Fragoso ${ }^{1}$; Paulo Hideo Nakano Rangel ${ }^{2}$; Raimundo Nonato Carvalho²; Expedito Alves \\ $\mathrm{Cardoso}^{3}$
}

\section{RESUMO:}

O objetivo desta nota científica é relatar a contribuição das cultivares da Embrapa para a produção de arroz no Tocantins. Cultivares de arroz são tecnologias de importância primária na produção, por isso deveriam ser consideradas no planejamento de plantios das lavouras pelos orizicultores tocantinenses. São anos de pesquisa, desde os cruzamentos iniciais de plantas, avaliações e selecão das linhagens para se obter um material com as características genéticas e fenótipicas desejáveis em uma cultivar de arroz melhorada. Na semente de uma cultivar desenvolvida pelo programa de melhoramento da Embrapa estão contidas características e fatores importantes como a pureza genética e fisíca, qualidade fisiológica e fitossanitária. A pureza genética garante ausência de misturas de outras cultivares no lote, cujos resultados são tolerância a doenças, uniformidade de plantas, melhor qualidade dos grãos e maior potencial produtivo. A pureza física garante ausência de impurezas como partículas de solo, restos vegetais, pedras, sementes danificadas, sementes de plantas daninhas e de outras espécies. A qualidade fisiológica trata-se da capacidade das sementes em gerarem plantas sadias, com maior vigor e germinação. Já a qualidade fitossanitária é garantia do uso de sementes livres de micro-organismos causadores de doenças. As principais contribuições das cultivares de arroz da Embrapa para a produção de arroz no Tocantins são aumento de $30 \%$ da produtividade nos últimos 10 anos, melhoria da qualidade industrial dos grãos com rendimento de grãos inteiros tipo 1 superior a $60 \%$ e tolerância às doenças, ocasionando uma redução de $50 \%$ na aplicação de produtos fitossanitários.

Palavras-chave: Oryza sativa, Melhoramento genético, Produtividade

\section{CONTRIBUTION OF EMBRAPA RICE CULTIVARS IN THE PRODUCTION OF IRRIGATED} RICE IN TOCANTINS STATE

\begin{abstract}
:
\footnotetext{
${ }^{1}$ Pesquisador da Embrapa Pesca e Aquicultura, Palmas, TO. E-mail: daniel.fragoso@embrapa.br

${ }^{2}$ Pesquisadores da Embrapa Arroz e Feijão, Santo Antônio de Goiás, GO.

${ }^{3}$ Pesquisador da Universidade Estadual do Tocantins, Palmas, TO.
} 
Revista Agri-Environmental Sciences, v. 7, Ed. Especial, e021005, 2021

DOI: https://doi.org/10.36725/agries.v7i2.5440

https://revista.unitins.br/index.php/agri-environmental-sciences/index

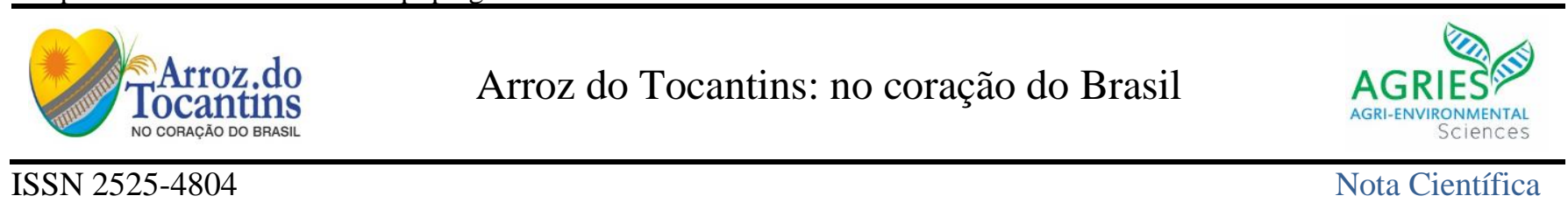

This scientific note aims to report the contribution of Embrapa cultivars to rice production in Tocantins State. Rice cultivars are technologies of primary importance in the production scale, and they must be considered in the planting planning of crops by Tocantins farmers. Since the initial plant crossing, it takes years of research before obtaining a material with the desirable genetic and phenotypic characteristics in an improved rice cultivar; this also includes evaluation and selection of strains. The seed of a cultivar developed by the Embrapa breeding program contains important characteristics such as genetic and physical purity, physiological and phytosanitary qualities. Genetic purity guarantees the absence of mixtures of other cultivars in a lot of seed, tolerance to diseases, uniformity of plants, a better quality of grains, and more significant productive potential. Physical purity guarantees the absence of impurities, such as soil particles, plant debris, stones, damaged seeds, weed seeds, and other species. Physiological quality is the ability of seeds to generate healthy plants with greater vigor and germination. On the other hand, phytosanitary quality guarantees the use of seeds free from microorganisms that cause disease. As a result of the main contributions of Embrapa to the production of rice cultivars in Tocantins is an increase of $30 \%$ in the productivity of the grain in the last ten years, improvement of the industrial quality with whole-grain yield type 1 more significant than $60 \%$ and tolerance to disease with reduction of $50 \%$ in the application of phytosanitary products.

Keywords: Oryza sativa, Plant Breeding, Productivity. 
A cadeia produtiva do arroz irrigado desempenha papel importante na geração de divisas e de empregos para o estado do Tocantins. Na safra 2020/2021, foram cultivados 111,2 mil hectares, com produção de 636,2 mil toneladas de arroz em casca (Conab, 2021). O cultivo está concentrado na região sudoeste do Estado, nas várzeas do vale dos rios Formoso, Javaés e Araguaia. Os principais municípios produtores são: Lagoa da Confusão, com área plantada de 50,7 mil hectares (ha); Formoso do Araguaia, com 21,8 mil ha; Dueré, com 15,2 mil ha; Pium, com 13,7 mil ha; Cristalândia, com 6,4 mil ha, e Santa Rita do Tocantins, com 3,4 mil ha (Fragoso et al., 2019).

Isso tem elevado a posição do Tocantins no cenário nacional como o terceiro maior produtor de arroz irrigado do Brasil, superado apenas pelo Rio Grande do Sul e Santa Catarina. Tal cenário é impulsionado, principalmente, pela adoção de tecnologias mais eficientes e pela forte atuação e organização da cadeia produtiva.

Devido a esse potencial de cultivo do arroz irrigado no estado, surgiram muitas empresas do ramo agroindustrial na região, incrementando o sistema de produção para tornar o arroz irrigado mais competitivo e atender aos anseios do mercado consumidor, principalmente, das regiões Centro-Oeste, Norte e Nordeste do país (Fragoso et al., 2013).

Com o crescimento do agronegócio, novos desafios foram surgindo para a região como a necessidade de lançamento de novas cultivares de arroz adaptadas às condições locais, adoção de tecnologias de prevenção ambiental e mitigação de efeitos climáticos, melhor utilização de água e manejo de culturas que resultem em maiores produtividades com o mínimo de impactos sobre o meio ambiente. $\mathrm{O}$ nível de tecnologia empregada faz com que a produtividade tenha variação de 70 a 120 sacas por hectare (Fragoso et al., 2013).

$\mathrm{Na}$ tentativa de se adaptar, atentando para a questão de restrições hídricas e maior eficiência do uso da água, os produtores têm optado por conduzir o arroz através de sub-irrigação ou solo saturado até a emissão da panícula. Ou seja, 70\% da duração do ciclo do arroz é sem lâmina de água, cuja inundação da lavoura ocorre apenas próximo à emergência da panícula.

Além da diferença de manejos nas áreas, pressão de doenças e luminosidade são dois fatores apontados pelos agricultores como os principais empecilhos para alcançar produtividades semelhantes às alcançadas pelos produtores do Sul do Brasil.

a) Pressão de doenças: o clima quente e úmido favorece a instalação e desenvolvimento de doenças com destaque para a Brusone. Enquanto no Sul do Brasil são feitas de duas a três aplicações para controle de doenças, no Tocantins, os produtores precisam de no mínimo seis aplicações para alcançar boas produtividades.

Dias Neto et al. (2010), realizaram um estudo utilizando isolados, coletados em lavouras comerciais de arroz irrigado no Vale do Rio Araguaia, nos estados do Tocantins e Goiás. Uma amostra de 479 isolados monospóricos de Magnaporthe oryzae foi obtida e testada no conjunto internacional de cultivares diferenciadoras de raças de brusone. Nos isolados testados, 61 patótipos de $M$. oryzae pertencentes a todos os grupos, exceto o grupo $\mathrm{IH}$, foram detectados. Isso demonstra que a região de cultivo do arroz do Vale do Rio Araguaia apresenta a maior diversidade de patótipos de Magnaporthe oryzae descrita até o momento, no Brasil. Isso explica a rápida quebra da resistência em cerca de dois anos de plantio das cultivares de arroz lançadas. Nas lavouras de arroz irrigado do Tocantins, as raças de brusone estão presentes em baixa frequência. Ao aumentar a área de plantio de uma determinada cultivar, a frequência da raça que ataca a referida cultivar aumenta, quebrando a resistência. 
b) Luminosidade: apesar de estar mais próximo ao Equador, Tocantins não possui o número suficiente de horas de sol durante o cultivo de arroz. A grande presença de nuvens durante o período, e consequente menor insolação e taxa fotossintética, é apontada por muitos como o principal fator para a diminuição da produtividade nas lavouras tecnicamente conduzidas. O uso de cultivares desenvolvidas para essas condições edafoclimáticas pode contribuir para superar essas limitações (ANA e CONAB, 2020).

Portanto, o maior desafio da orizicultura no Tocantins é garantir a sustentabilidade da atividade. Isso requer o aumento de rentabilidade com base na redução de custos de produção, aumento de produtividade e da qualidade do produto, bem como a minimização de riscos de impactos ambientais negativos (Fragoso et al., 2013).

\section{CONTRIBUIÇÃO DAS CULTIVARES DA EMBRAPA PARA A PRODUÇÃO DE ARROZ NO TOCANTINS}

Esse cenário exige do melhoramento genético de arroz da Embrapa Arroz e Feijão uma maior agilidade de desenvolvimento de linhagens elite para região tropical do Brasil, não somente de elevado potencial produtivo, mas com a presença de tolerância à herbicida, resistência genética às principais doenças da cultura, com ciclos de maturação distintos (precoce e médio) para permitir o escalonamento de plantio e colheita, e com a presença de grãos "nobres" tanto em aspectos industriais quanto culinários.

Como exemplo, as cultivares de arroz BRS Catiana, BRS Pampeira e BRS A702 CL, recentemente lançadas para cultivo nas várzeas do Estado do Tocantins, que além das características favoráveis possuem elevada resistência a brusone. Essas três cultivares têm reduzido drasticamente a utilização de agrotóxicos, contribuindo para uma maior rentabilidade das lavouras de arroz e preservação do meio ambiente. Juntas, essas cultivares representaram $78 \%$ de toda produção de arroz do Tocantins, ou seja, dos 108 mil hectares de área plantada com arroz irrigado na safra 2018/2019, foram cultivados 84 mil hectares, sendo 53.550 ha (49\%) com a BRS Pampeira; 27.195 ha (26\%) com a BRS Catiana e 3.168 ha (3\%) com a BRS A702 CL. Na safra 2019/2020 o percentual de uso das cultivares de arroz da Embrapa aumentou para cerca de $90 \%$.

Com o objetivo de avaliar a contribuição das cultivares na redução do uso de fungicidas nos cultivos de arroz irrigado no Tocantins foram levantadas informações sobre o número de pulverizações realizadas nas safras 2016/2017 em áreas plantadas com cultivares que tiveram a sua resistência quebrada e, 2017/2018, em áreas plantadas com as cultivares BRS Catiana e BRS Pampeira. Com base nas informações obtidas junto a produtores de arroz irrigado e revendas de defensivos agrícolas, por meio de questionários, todos responderam que as cultivares BRS Catiana e BRS Pampeira contribuíram para reduzir o uso de fungicidas nos cultivos de arroz irrigado na região sudoeste do estado do Tocantins. Nas áreas plantadas com as duas cultivares resistentes em substituição a cultivar susceptível, o número de pulverizações foi reduzido de oito, na safra 2016/2017, para em média três pulverizações na safra 2017/2018; uma delas, no estádio vegetativo e duas no estádio reprodutivo.

Considerando que na safra 2017/2018 foram plantados cerca de 100 mil hectares, e que a área plantada com essas duas cultivares representou cerca de $50 \%$ da área total, tem se uma redução pela metade do uso de fungicidas. Isso é positivo do ponto de vista ambiental, bem como para os produtores de arroz, por reduzir o custo de produção (Fragoso et al., 2019).

\section{BRS PAMPEIRA}


A cultivar BRS Pampeira foi lançada para cultivo em 2016. Ela apresenta porte moderno de plantas com folhas eretas e elevado perfilhamento. Além disso, os colmos são fortes, com resistência ao acamamento de plantas; apresenta tolerância às principais doenças do arroz, em especial, a brusone; e tem elevada produtividade de grãos. O ciclo biológico da BRS Pampeira gira em torno de 120 dias da emergência à maturação. Os grãos são do tipo longo fino considerado "nobres" com rendimento industrial dos grãos, em condições normais de ambiente e manejo da lavoura, superior a $62 \%$ de grãos inteiros polidos, $6 \%$ de grãos quebrados e renda de $68 \%$. Hoje, a BRS Pampeira é a cultivar mais plantada no Estado do Tocantins.

\section{BRS CATIANA}

A cultivar BRS Catiana foi lançada também em 2016 e apresenta características agronômicas semelhantes à da BRS Pampeira. Ela apresenta porte moderno com folhas eretas, elevado perfilhamento e os colmos são fortes, com resistência ao acamamento de plantas. É tolerante às principais doenças do arroz, em especial a brusone, e possui elevada produtividade de grãos. O ciclo biológico da BRS Catiana gira em torno de 120 dias da emergência à maturação. Os grãos são do tipo longo fino considerado "nobres" com um rendimento industrial dos grãos, em condições normais de ambiente e manejo da lavoura, superior a $62 \%$ de grãos inteiros polidos, $6 \%$ de grãos quebrados e renda de $68 \%$.

\section{BRS A702 CL}

A BRS A702 CL foi lançada em 2018 e possui como principal característica a tolerância a herbicida, sendo a primeira cultivar lançada especificamente para cultivo nas várzeas do Tocantins. Ela se caracteriza por apresentar elevada produtividade de grãos, em ciclo curto, demonstra alta tolerância ao acamamento, além de ter adequada qualidade industrial e culinária dos grãos e tolerância genética ao herbicida Kifix ${ }^{\circledR}$ de largo espectro. Uma vantagem que impacta positivamente no custo final de produção é a redução na quantidade de aplicações de herbicidas, pois permite reduzir de cinco para apenas duas aplicações, no máximo.

\section{BRS A704}

A cultivar BRS A704 foi lançada para cultivo no Estado do Tocantins, em 2020, durante a Agrotins. Uma característica marcante dela é a sua ampla base genética, tendo no seu pedigree 14 fontes de resistência à brusone. A diversificação de genes de resistência à brusone é de suma importância no controle dessa doença. A BRS A704 foi avaliada para resistência a brusone em 45 ambientes e, na maioria deles, apresentou notas inferiores à das cultivares BRS Pampeira e BRS Catiana. Ela apresenta porte moderno de plantas com folhas eretas e elevado perfilhamento. Os colmos são fortes, com resistência ao acamamento de plantas e apresenta tolerância às principais doenças do arroz, em especial à brusone, e possui elevada produtividade de grãos. A BRS A704 é considerada de ciclo médio que gira em torno de 120 dias da emergência à maturação. Os grãos são do tipo longo fino considerado "nobre", com rendimento industrial dos grãos, em condições normais de ambiente e manejo da lavoura de $67 \%$ de grãos inteiros polidos. O teor de amilose é de $23 \%$, considerado intermediário, e a temperatura de gelatinização é baixa com nota 7. Possui área gessada total de 7,9\% inferior à das cultivares BRS Catiana e BRS Pampeira.

\section{AGRADECIMENTOS}

Aos pesquisadores, técnicos e parceiros do Programa de Melhoramento de Arroz da 
Embrapa - Melhor Arroz. À Universidade Estadual do Tocantins - UNITINS pela cooperação técnica para condução de trabalhos de pesquisas e de transferência de tecnologias no Centro de Pesquisa Agroambiental da Várzea CPAV, em Formoso do Araguaia-TO.

\section{REFERÊNCIAS BIBLIOGRÁFICAS}

Agência Nacional De Águas E Saneamento Básico (ANA), Companhia Nacional De Abastecimento (Conab). (2020). Mapeamento do arroz irrigado no Brasil. Brasília: ANA, 40 p.
Companhia Nacional De Abastecimento (Conab). (2021). Acompanhamento safra brasileira: grãos. Safra 2020/21 $6^{\circ}$ levantamento. Vol.8-, n.6 Brasília: Conab, p. 1106.

Fragoso, D.B.; Rangel, P.H.N.; Custodio, D.P.; Cardoso, E.A (2019). Caracterização da produção de arroz irrigado tropical na região sudoeste do estado do Tocantins. In: Congresso Brasileiro de arroz irrigado, 11. Balneário Camboriú: Anais, p. 1-4.

Fragoso, D.B.; Cardoso, E.A.; Souza, E.R.; Ferreira, C.M. (2013). Caracterização e diagnóstico da cadeia produtiva do arroz no estado do Tocantins. Brasília: Embrapa. 40p. 